
About IJMA [last updated July, $\left.1^{\text {st }}, 2021\right]$

$\checkmark$ International Journal of Medical Arts is the Official Journal of the Damietta Faculty of Medicine, AlAzhar University, Egypt

$\checkmark$ It is an International, Open Access, Double-blind, Peer-reviewed Journal

$\checkmark$ Published four times a year

$\checkmark$ The First Issue was published in July 2019

$\checkmark$ Published under the following license: Creative Commons Attribution-ShareAlike 4.0 International Public License (CC BY-SA 4.0). It had updated from the Creative Commons license [CC BY] in volume 2, Issue 4, October 2020 About IJMA

$\checkmark$ The Egyptian Knowledge Bank hosts the web site of IJMA

$\checkmark$ The Egyptian Knowledge Bank supports IJMA

$\checkmark$ IJMA follows the regulations of the International Committee of Medical Journal Editors

$\checkmark$ IJMA is indexed in the "Directory of Open Access Journals" [15 January 2021].

$\checkmark$ IJMA is indexed in JGate [29-6-2021]

$\checkmark$ IJMA is a member of the International Society of Managing and Technical Editors

$\checkmark$ Listed in "Index Copernicus", "Publons", "Academic resource index [ResearchBib]", "Electronics journal library", "Eurasian Scientific Journal Index", and "Citefactor"

$\checkmark$ IJMA introduced to the search engine [BASE] through DOAJ
Click image to reach the page

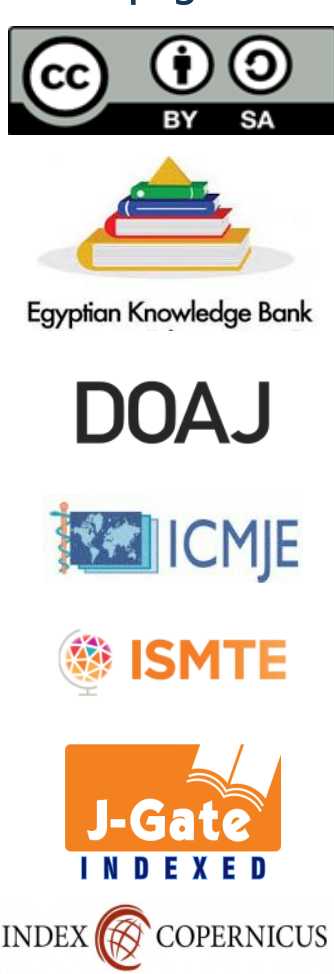

publons

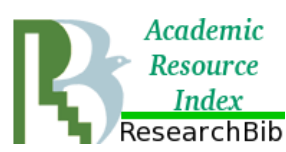

\section{EZ3 \\ .}

ESJII

CiteFactor

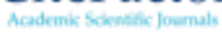

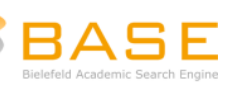




Available online at Journal Website
https://ijma.journals.ekb.eg/
Main subject [Orthopedics; Traumatology]

Original Article

\title{
Outcome of Open Reduction and Internal Fixation of Posterior Acetabular Fractures
}

\author{
Shady Abdou Goda; Asharaf El Tabie Ezzedeen; Osman Abd Ellah Mohamed Elsherif \\ Department of Orthopedic Surgery, Damietta Faculty of Medicine, Al-Azhar University, Egypt.
}

Corresponding author: Shady Abdou Goda

Email: shadygoda.sg@gmail.com

Submission date: April 11, 2021; Acceptance date: August 03, 2021

DOI: 10.21608/IJMA.2021.72017.1296

\section{ABSTRACT}

Background: Acetabular fractures are a common clinical challenge. The posterior wall fractures represented $35 \%$ of all acetabular fractures and usually complexed. The curative treatment is surgical and depends on the fracture anatomy and surgeon preferences.

Aim of the Work: The current study aimed to assess the short term results of posterior acetabular fractures management by open reduction and internal fixation.

Patients and Methods: Thirty patients with displaced posterior wall acetabular fractures were included. They were treated by open reduction and internal fixation using neutralizing plates and screws. All patients were assessed by a preprepared trauma assessment sheet. Post-operative, active assisted and pain free passive range of motion exercises in all planes was advised. Functional outcome was evaluated using the Merle D'Aubinge and Postel score. Patients were followed up initially at 3 weeks intervals for first 2 months and thereafter at 6 weekly intervals for the next 6 months.

Result: Patients were classified to two groups: Group [A] "70\%" patients with isolated posterior wall fracture, and Group [B] "30\%" of patients with posterior column plus posterior wall acetabular fracture. Both groups were comparable regarding age, gender, side and mode of trauma. The double plating fixation method was significantly increased in group B when compared to group A [77.8\% vs. $0.0 \%$ respectively]. Group B was associated with significant increase of operative time than group A [164.44 \pm 13.33 vs. $128.57 \pm 27.80$ minutes, respectively]. Blood loss significantly increased in group B than group A [1422.22 \pm 376.76 vs. $780.95 \pm 437.46 \mathrm{ml}$, respectively]. The excellent outcome was significantly associated with younger age, lower or absent complications, and anatomical [good quality] of direct postoperative radiological outcome.

Conclusion: Most of our patients had an excellent and good outcome as a result to application of more strict selection criteria of patients and pattern.

Keywords: Acetabulum; Posterior Wall; Fractures; Open Reduction; Internal Fixation.

This is an open-access article registered under the Creative Commons, ShareAlike 4.0 International license [CC BY-SA 4.0] [https://creativecommons.org/licenses/by-sa/4.0/legalcode.

Citation: Goda SA, Ezzedeen AE, Elsherif OAM. Outcome of Open Reduction and Internal Fixation of Posterior Acetabular Fractures. IJMA 2021; 3 [3]: July-September: 1724-1734. [DOI: 10.21608/IJMA.2021.72017.1296].

${ }^{*}$ Main subject and any subcategories have been classified according to the research topic. 


\section{INTRODUCTION}

The acetabulum is made up of a segment of innominate bone. It is located where the ilium, ischium, and pubic bone are connected by tri-radiate cartilages, which then fuse to form an innominate bone. The acetabulum is encircled by anterior and posterior columns resembling the 2 limbs of inverted $Y$ shape ${ }^{[1]}$.

In $35 \%$ of acetabular fractures, the posterior wall had been involved, being is the most common affected, with about $76 \%$ of these injuries had complex fractures [2].

Patients often have multiple traumatic injuries, [in up to $50 \%$ of patients]. Resuscitation followed by gentle reduction posterior dislocations on an emergent basis then local orthopedic examination includes the assessment of the following: Position of the lower limb, skin condition, limb length inequality and neurologic examination ${ }^{[3]}$.

There are many classifications of acetabular fractures, but the simplest classification was made by Judet and Letournel, who classify acetabular fracture based on the fracture anatomy as a single fracture pattern, with only one fracture line. Types include posterior wall fractures, posterior column fractures, anterior wall fractures, anterior column fractures and transverse fractures ${ }^{[4]}$.

Fractures of the acetabulum were treated nonoperatively till the middle of the $20^{\text {th }}$ century. After several progressions, acetabular surgery has become the accepted standard for the treatment of almost all displaced acetabular fractures ${ }^{[5]}$

In posterior wall fracture, in case of adequate fragment size, one or two isolated inter-fragmentary lag screws is used to fix the reduced fragments, make sure to insert every screw extra-articularly ${ }^{[6]}$.

In posterior column fracture, fixation of the posterior column fracture, with one or two inter-fragmentary lag screws can be applied [7].

Neutralization plate with a pre-contoured pelvic reconstruction plate applied to the surface of the posterior column. The plate bridges the reduced fragment and extends superiorly to the outer part of the iliac fossa. Inferiorly it extends to the intact part of the ischium ${ }^{[8]}$.

Preoperative evaluation is used to rule out other injuries. The ideal operation time is 3-10 days after injury ${ }^{[9]}$.

The selection of approach usually depends on the anatomy of the fracture, but it also depends on the surgeon's personal preference and experience. Posterior wall/column fractures are approached by Kocher-Langenbeck [10].

The purpose of postoperative management is to augment the functional status of patients, promote early functional recovery, and quickly detect complications and control them properly [11].

Complications of acetabular fractures include massive pulmonary embolism, infection, sciatic nerve damage, vascular injury, thrombo-embolism, malreduction and fixation failure. Late complications include avascular necrosis, posttraumatic osteoarthritis, heterotropic new bone formation and chondrolysis ${ }^{[12]}$.

Outcome and prognosis affected by several factors like the injury pattern, force of energy, location, degree of articular comminution and degree of initial displacement [13].

In general, isolated posterior wall fractures are considered to have a good prognosis, but recent reviews have shown that $21 \%$ and $32 \%$ of patients have a poor prognosis [2].

\section{THE AIM OF THE WORK}

The aim of this study is to evaluate the short term results in management of posterior acetabular fractures by open reduction and internal fixation.

\section{PATIENTS AND METHODS}

Between January 2017 \& January 2020, 30 patients with displaced posterior acetabular fractures underwent open reduction and internal fixation by neutralizing plates lag screws. Cases were operated in Damietta AL-Azhar University Hospital.

The study included patients with posterior acetabular fractures; in all cases the surgery was indicated. We excluded patients with open fractures, and patients refusing to join the study after explaining risks and benefits. There were no selection limitations for age and sex. Average follow up was 9 months [ranging from 6 and 12 months].

Inclusion criteria are: skeletally mature patient, within 2 weeks of trauma, unstable posterior wall/column acetabular fractures, co-operative medically fit patient, and primary intervention.

Exclusion Criteria are: open fractures of acetabulum, stable posterior wall/ column acetabular fractures not requiring surgery, active infection of the hip joint and /or the 
surrounding soft tissue, patients with severe osteoarthritis hip joint [for THR from the start], non-ambulatory patient, and pathologic fractures of acetabulum.

The majority of the patients [21] were isolated posterior wall acetabular fractures [70\%] and [9] were posterior column \pm wall fractures [30\%]; and 15 patients had associated fractures. Fifteen Patients had associated injury. The site of injury was head [2 patients], chest, abdomen, genitourinary [each in one patient], pelvic ring [3 patients], upper limp [one patient], lower limb [8 patients; one in femur, 1 for patella, one for tibia, 3 in tibial plateau, and 2 medial malleoli]. There was nerve injury in 3 patients [one in sciatic nerve and two in common peroneal nerves around the knee].

The primary survey: All Patients were managed according to the Advanced Trauma Life Support Protocol [ATLS], and Life threatening situations were dealt with accordingly. Otherwise, the secondary survey included mode and date of trauma, past medical history, clinical examination and neurovascular assessment, and all patients were assessed by a pre-prepared trauma assessment sheet.

This sheet included patient history, medical history, trauma history, primary survey [airway, breathing, circulation, disability and environment], secondary survey [head, chest, spine, pelvis and extremities], laboratory workup [complete blood count, random blood sugar, renal, liver and bleeding profiles], and radiology [pelvis, spine, extremities, abdominal ultrasound, Computed tomography of the pelvis and acetabulum]. The diagnosis of acetabular fracture was classified according to Judet and Letourne ${ }^{[4]}$.

Pre-operative interval: Patients were operated upon after a mean of 7 days [range $3-13$ days], from the date of trauma. Many factors affected the time till surgery, including the time between the actual trauma and the date of admission to the hospital; general condition of the patients (five patients were admitted first to ICU) and the accessibility of blood units for intraoperative blood transfusion. Three patients had type B blood and two patients had type AB-, one patient $\mathrm{O}-$, all of this causes significant delay in the operative date.

\section{Management after admission and pre -operative preparation:}

Prophylaxis with enoxaparin $40 \mathrm{mg} \mathrm{SC} / 24$ hours to prevent deep venous thrombosis. It was stopped 12 hours before surgery. Electrocardiogram [ECG] was done for all patients more than 40 years of age. Registration of 4 units of whole blood was completed and all patients received one dose of 3rd generation Cephalosporin within one hour before incision.

\section{Operative details:}

All patients were prepared and draped in a lateral position [Figure 1]. All fractures were exposed and stabilized through K-L approach in lateral position with the affected hip on the upper side [Figures 2 and 3].

The approach started by cleaning off the soft tissue debris between the fractured fragments and preservation of the attached capsular soft tissues [Figure 4].

Free osteochondral fragments in the hip joint are cleaned and the degree of margin impaction was recognized by the application of gentle traction at the hip joint [Figure 5]. Then reduction of posterior wall fragments and their supporting capsular ligaments was done and maintained with a pointed ball spike. Using a ball spike instrument leads to reduction of the necessity of momentary fixation by Kirshiner wires [Figure 6].

Kirshiner wires were sometimes used provisionally till final fixation was done. All patients treated with open reduction and internal fixation with reconstruction plate 3.5 $\mathrm{mm}$ and cancellous screws $4 \mathrm{~mm}$ [Figure 7].

When the smaller fragments are disconnected from the soft tissue, they are discarded. After fixation, gently traction the hip joint and confirm the intra-articular reduction through a stability test. Care was considered to make sure that the lag screw placed near the posterior edge is extra-articular. The wounds were closed in layers over suction drainage tubes. The drains were removed at $48-72 \mathrm{hrs}$.

In cases with posterior column fractures, the fracture can be distracted carefully with a lamina spreader or with distal fragment manipulation via a Schanz screw applied to the ischial tuberosity. During the final reduction of the posterior column, the femoral head must be fully reduced relative to the stable superior-anterior part of the acetabulum. Therefore, the femoral head becomes a template for the full reduction of the posterior column. Incorrect head position can hinder fracture reduction.

Reduction of posterior column can be aided by special instruments as pointed reduction forceps or Farabeuf clamp and Once an anatomic reduction is obtained, provisional fixation is added to augment the clamp acquired reduction by inter-fragmentary lag screw or a short plate across the fracture can be applied along the medial edge of the posterior column and a second plate along the acetabular margin will also be necessary [Figure 8]. 


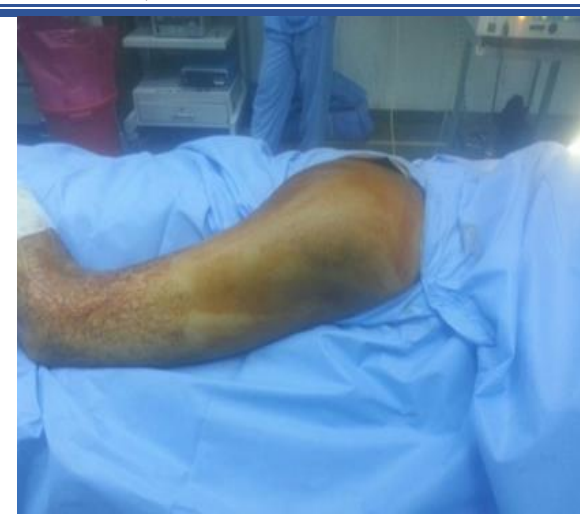

Figure [1]: Lateral position of the patient and draping

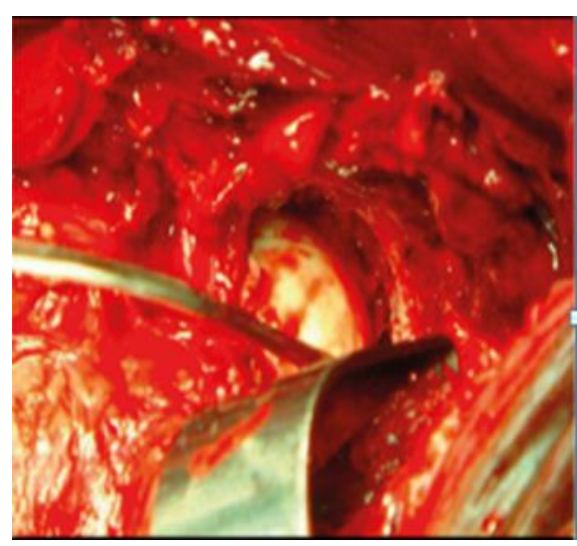

Figure [4]: Cleaning of the fracture site

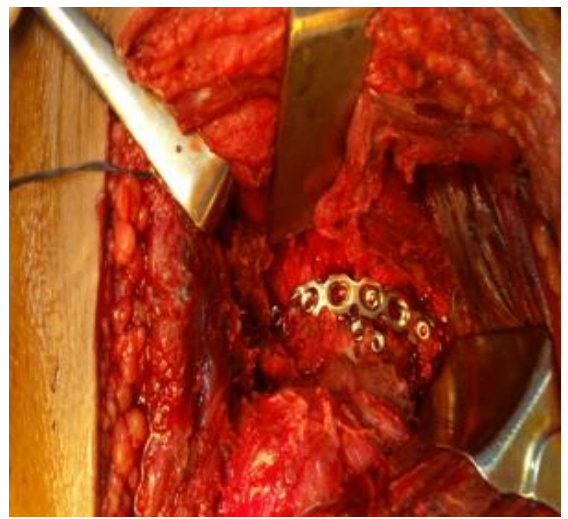

Figure [7]: Fixation of posterior wall by underbent plate with 2 lag screws

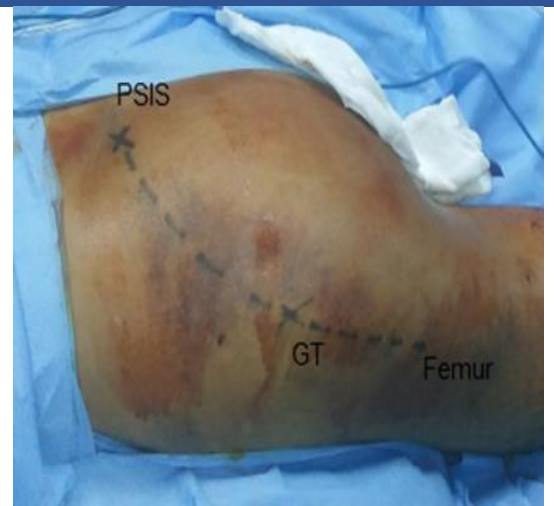

Figure [2]:Bony landmarks of skin incision; PSIS: posterior superior iliac spine; GT: greater trochanter

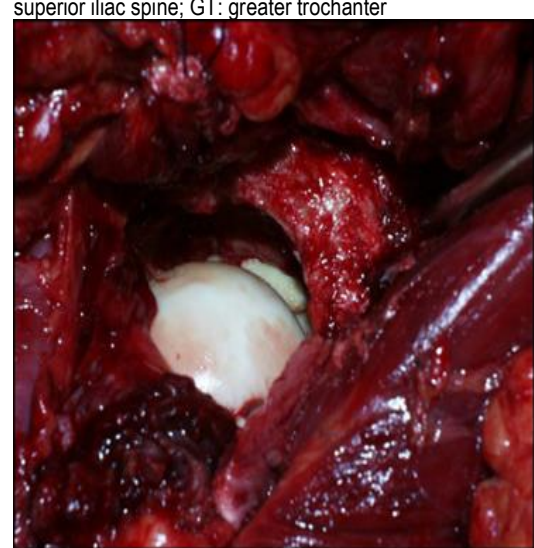

Figure [5]: Removal of loose body

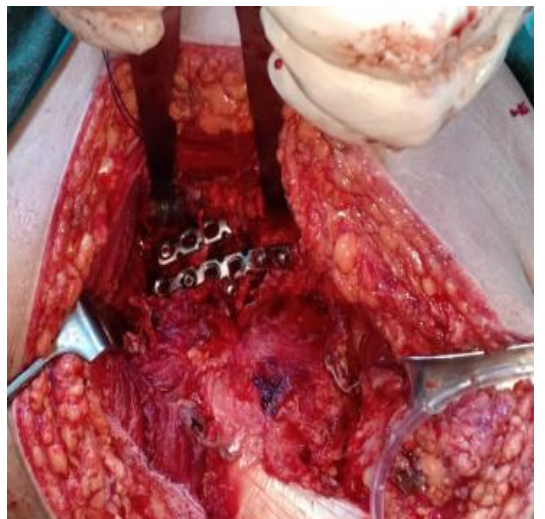

Figure [8]: Fixation of posterior column by short plate with additional long plate

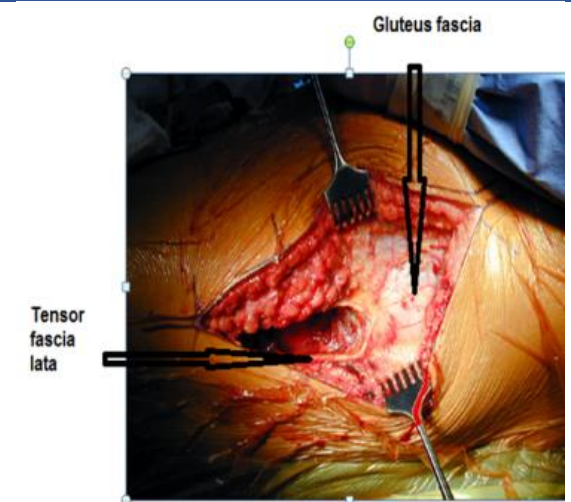

Figure [3]:Fascial incision

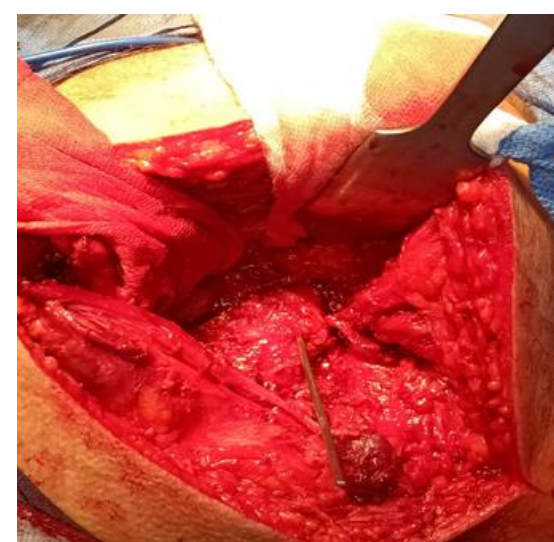

Figure [6]: Reduction of posterior wall and temporary fixation by K-wire
Post-operative, active assisted and pain free passive range of motion exercises in all planes was advised. Postoperatively, patients were instructed to use crutches on the affected extremity. Partial weight bearing was allowed after 6 weeks and full weight-bearing with a single crutch or a cane after 10-12 weeks. Unprotected weight bearing was advised after complete healing of the fracture. Immediate postoperative radiographs in three views were reviewed to evaluate reduction accuracy, and follow-up radiographs were reviewed to evaluate for any loss of reduction. Displacement $0-1 \mathrm{~mm}$ was graded as anatomical, $2-3 \mathrm{~mm}$ as satisfactory, $>3 \mathrm{~mm}$ as poor.
Functional outcome was evaluated using the Merle D'Aubinge and Postel score, divided into several items such as pain, range of motion and walking distance, with a clinical score 18 as excellent and [15-17] known as Good, while score from [13-14] considered fair, and poor grade with score $<13$. The final radiological outcomes were graded according to the criteria developed by Matta. According to these criteria, "a grade of excellent is given to a normal appearing hip joint, good denotes mild changes with minimal sclerosis and joint narrowing, fair indicates intermediate changes with moderate sclerosis and joint narrowing $[<50 \%]$ and poor signifies advanced changes". Patients were followed up initially at three weeks' intervals for first two 
months and thereafter at 6 weekly intervals for the next six months. Any complications that occurred during the followup period were documented.

Ethical considerations: All patients had signed informed consent, and the study protocol was accepted by the staff members of orthopedic department, Damietta ALAzhar University.

\section{Statistical analysis and data interpretation}

Data were fed to the computer and analyzed using IBM SPSS Corp. Released 2013. IBM SPSS Statistics for Windows, Version 22.0. Armonk, NY: IBM Corp. Qualitative data were described using number and percent.

Quantitative data were described using median [minimum and maximum] for non-parametric data and mean, standard deviation for parametric data after testing normality using Shapiro-Wilk test.

Significance of the obtained results was judged at the [0.05] level. Chi-Square test for comparison of 2 or more groups. Monte Carlo test as correction for Chi-Square test when more than $25 \%$ of cells have count less than 5 in tables [ $\left.>2^{*} 2\right]$. Fischer Exact test was used as correction for Chi-Square test when more than $25 \%$ of cells have count less than 5 in $2 * 2$ tables. Student t-test was used to compare 2 independent groups. One Way ANOVA test was used to compare more than 2 independent groups with Post Hoc Tukey test to detect pair-wise comparison

\section{RESULTS}

Between January 2017 and January 2020 we operated upon 30 posterior acetabular fractures. Patients were then followed up for a mean period of 9 months [Range: 6 to 12 months].
For the sake of data presentation and statistical analysis the study patients were classified to two groups: Group [A] "70\%" patients with isolated posterior wall fracture, and Group [B] "30\%" patients with posterior column \pm posterior wall acetabular fracture.

Table [1] presented patient demographics, injury characteristics and fixation method. Both groups were comparable regarding patient age, patient gender, side of injury and mode of trauma. The double plating fixation method was significantly increased in group $B$ when compared to group A $[77.8 \%$ vs $0.0 \%$ respectively]. However, plate screw fixation was significantly reduced in group B than group A [22.2\% vs $100.0 \%]$.

Regarding operative and postoperative details, group B is associated with significant increase of operative time than group A [164.44 \pm 13.33 vs $128.57 \pm 27.80$ minutes, respectively].

In addition, blood loss significantly increased in group $B$ when compared to group A [1422.22 \pm 376.76 vs $780.95 \pm 437.46 \mathrm{ml}$, respectively].

Otherwise no significant differences were found regarding the time to surgery [days], blood transfusion units, postoperative radiographic outcome, postoperative complications, clinical and radiological outcomes [Table 2].

The excellent outcome was significantly associated with younger age, lower or absent complications, and anatomical [good quality] of direct postoperative radiological outcome [Table 3].

Excellent late radiological outcome was significantly associated with lower postoperative complications, and good [anatomical] reduction at direct postoperative radiography [Table 4]

Table [1]: Patient demographics

\begin{tabular}{|c|c|c|c|c|c|}
\hline \multicolumn{2}{|c|}{ Variables } & Group A [n=21] & Group B [n=9] & test & $P$ \\
\hline \multicolumn{2}{|l|}{ Age [year] } & $33.48 \pm 8.49$ & $37.22 \pm 13.98$ & 0.907 & 0.372 \\
\hline \multirow{2}{*}{$\begin{array}{l}\text { Sex } \\
{[n, \%]}\end{array}$} & Male & $20[95.2 \%]$ & $8[88.9 \%]$ & \multirow[t]{2}{*}{0.408} & \multirow[t]{2}{*}{0.517} \\
\hline & Female & $1[4.8 \%]$ & $1[11.1 \%]$ & & \\
\hline \multirow[t]{2}{*}{ Side of injury } & Right & $10[47.6 \%]$ & $3[33.3 \%]$ & \multirow[t]{2}{*}{0.524} & \multirow[t]{2}{*}{0.469} \\
\hline & Left & $11[52.4 \%]$ & $6[66.7 \%]$ & & \\
\hline \multirow[t]{3}{*}{ Mode of trauma } & FFH & $2[9.5 \%]$ & $1[11.1 \%]$ & \multirow[t]{3}{*}{1.42} & \multirow[t]{3}{*}{0.490} \\
\hline & MCA & $5[23.8 \%]$ & $4[44.4 \%]$ & & \\
\hline & RTA & $14[66.7 \%]$ & $4[44.4 \%]$ & & \\
\hline \multirow[t]{4}{*}{ Fixation method } & Spring plate & $2[9.5 \%]$ & $1[11.1 \%]$ & 0.02 & 0.67 \\
\hline & Double plating & $0[0.0 \%]$ & $7[77.8 \%]$ & 21.30 & $<0.001^{*}$ \\
\hline & Anterior screw & $2[9.5 \%]$ & 1[11.1\%] & FE & 0.67 \\
\hline & Plate screw & $21[100.0 \%]$ & $2[22.2 \%]$ & 21.30 & $<0.001^{*}$ \\
\hline
\end{tabular}




\begin{tabular}{|c|c|c|c|c|c|}
\hline & & $\begin{array}{c}\text { Group A } \\
n=21\end{array}$ & $\begin{array}{c}\text { Group B } \\
n=9\end{array}$ & Test & $p$ \\
\hline \multirow[t]{4}{*}{ Operative } & Time to surgery/days & $6.38 \pm 2.76$ & $7.33 \pm 2.64$ & 0.875 & 0.389 \\
\hline & Blood loss $/ \mathrm{cm}$ & $780.95 \pm 437.46$ & $1422.22 \pm 376.76$ & 3.82 & $<0.001^{*}$ \\
\hline & Operative time / minutes & $128.57 \pm 27.80$ & $164.44 \pm 13.33$ & 3.67 & $<0.001^{*}$ \\
\hline & Blood transfusion units & $4.92 \pm 2.64$ & $4.75 \pm 2.87$ & 0.306 & 0.760 \\
\hline \multirow[t]{3}{*}{ PO radiography } & Unsatisfactory & $1[4.8 \%]$ & $1[11.1 \%]$ & \multirow[t]{3}{*}{0.47} & \multirow[t]{3}{*}{0.78} \\
\hline & Satisfactory & $6[26.8 \%]$ & $2[22.2 \%]$ & & \\
\hline & Anatomical & $14[66.7 \%]$ & $6[66.7 \%]$ & & \\
\hline \multirow{5}{*}{$\begin{array}{l}\text { PO } \\
\text { complications }\end{array}$} & None & $15[71.4 \%]$ & $7[77.8 \%]$ & \multirow[t]{5}{*}{2.15} & \multirow[t]{5}{*}{0.643} \\
\hline & Deep infection \& AVN & $1[4.8 \%]$ & $1[11.1 \%]$ & & \\
\hline & Neuropraxia of scitic nerve & $3[14.3 \%]$ & $0[0.0 \%]$ & & \\
\hline & Osteoporosis & $1[4.8 \%]$ & $0[0.0 \%]$ & & \\
\hline & Superficial infection & $1[4.8 \%]$ & $1[11.1 \%]$ & & \\
\hline \multirow[t]{4}{*}{ Clinical outcome } & Poor & $2[9.5 \%]$ & $1[11.1 \%]$ & \multirow[t]{4}{*}{0.37} & \multirow[t]{4}{*}{0.946} \\
\hline & Fair & $2[9.5 \%]$ & $1[11.1 \%]$ & & \\
\hline & Good & $10[47.6 \%]$ & $5[55.6 \%]$ & & \\
\hline & Excellent & $7[33.3 \%]$ & $2[22.2 \%]$ & & \\
\hline \multirow{4}{*}{$\begin{array}{l}\text { Radiological } \\
\text { outcome }\end{array}$} & Poor & $2[9.5 \%]$ & $1[11.1 \%]$ & \multirow[t]{4}{*}{0.56} & \multirow[t]{4}{*}{0.905} \\
\hline & Fair & $1[4.8 \%]$ & $0[0.0 \%]$ & & \\
\hline & Good & $10[47.6 \%]$ & $5[55.6 \%]$ & & \\
\hline & Excellent & $8[38.1 \%]$ & $3[33.3 \%]$ & & \\
\hline
\end{tabular}

Table [3]: Relation between clinical outcome and studied variables

\begin{tabular}{|c|c|c|c|c|c|c|c|}
\hline \multirow{2}{*}{\multicolumn{2}{|c|}{ Variables }} & \multicolumn{4}{|c|}{ Clinical outcome } & \multirow[t]{2}{*}{ Test } & \multirow[t]{2}{*}{$P$ value } \\
\hline & & \multirow{2}{*}{$\begin{array}{c}\begin{array}{c}\text { Poor } \\
{[n=3]}\end{array} \\
36.33 \pm 10.97 \\
\end{array}$} & \multirow{2}{*}{$\begin{array}{c}\begin{array}{c}\text { Fair } \\
{[n=3]}\end{array} \\
25.33 \pm 8.737 \\
\end{array}$} & \multirow{2}{*}{$\begin{array}{c}\text { Good } \\
{[n=15]} \\
39.40 \pm 9.869\end{array}$} & Excellent [n=9] & & \\
\hline & Age & & & & $29.11 \pm 7.541$ & 3.46 & $0.031^{*}$ \\
\hline \multirow[t]{2}{*}{ Sex } & Male & $3[100.0 \%]$ & $3[100.0 \%]$ & $13[86.7 \%]$ & $9[100.0 \%]$ & \multirow[t]{2}{*}{2.14} & \multirow[t]{2}{*}{0.543} \\
\hline & Female & $0[0.0 \%]$ & $0[0.0 \%]$ & $2[13.3 \%]$ & $0[0.0 \%]$ & & \\
\hline \multirow[t]{2}{*}{ Side } & Right & $0[0.0 \%]$ & $2[66.7 \%]$ & $8[53.3 \%]$ & $3[33.3 \%]$ & \multirow[t]{2}{*}{3.93} & \multirow[t]{2}{*}{0.268} \\
\hline & Left & $3[100.0 \%]$ & $1[33.3 \%]$ & $7[46.7 \%]$ & $6[66.7 \%]$ & & \\
\hline \multirow{3}{*}{$\begin{array}{l}\text { Mechanism } \\
\text { of injury }\end{array}$} & FFH & $0[0.0 \%]$ & $0[0.0 \%]$ & $3[20.0 \%]$ & $3[100.0 \%]$ & \multirow[t]{3}{*}{7.55} & \multirow[t]{3}{*}{0.273} \\
\hline & MCA & $2[66.7 \%]$ & $0[0.0 \%]$ & $5[33.3 \%]$ & $2[22.2 \%]$ & & \\
\hline & RTA & $1[33.3 \%]$ & $3[100.0 \%]$ & $7[46.7 \%]$ & $7[77.8 \%]$ & & \\
\hline \multicolumn{2}{|c|}{ Time to support/day } & $6.33 \pm 1.155$ & $7.67 \pm 3.0$ & $6.87 \pm 2.416$ & $6.33 \pm 3.61$ & 0.280 & 0.840 \\
\hline \multicolumn{2}{|l|}{ Blood loss [ml] } & $933.3 \pm 57.7$ & $883.3 \pm 707.6$ & $1133.3 \pm 554.0$ & $750.0 \pm 416.0$ & KW & 0.335 \\
\hline \multicolumn{2}{|c|}{ Operative time [min] } & $143.3 \pm 11.5$ & $136.6 \pm 25.1$ & $148.0 \pm 25.6$ & $124.4 \pm 37.1$ & 1.269 & 0.306 \\
\hline \multicolumn{2}{|c|}{ Blood transfusion [unit] } & $2.0 \pm 0.0$ & $1.67 \pm 1.155$ & $2.3 \pm 1.1$ & $1.56 \pm 1.13$ & 1.016 & 0.402 \\
\hline \multirow{4}{*}{$\begin{array}{l}\text { Fixation } \\
\text { method }\end{array}$} & \begin{tabular}{|l|} 
Spring plate \\
\end{tabular} & $0[0.0]$ & $1[33.3]$ & $2[13.3]$ & $0[0.0]$ & \multirow[t]{4}{*}{$M C$} & \multirow[t]{4}{*}{0.34} \\
\hline & Double plating & $0[0.0]$ & $0[0.0]$ & $5[33.3]$ & 2 222.2] & & \\
\hline & Anterior screw & $0[0.0]$ & $1[33.3]$ & $2[13.3]$ & $0[0.0]$ & & \\
\hline & Plate \& screw & $3[100.0]$ & $3[100.0]$ & $10[66.7]$ & $7[77.8]$ & & \\
\hline \multirow{5}{*}{$\begin{array}{c}\mathrm{PO} \\
\text { complications }\end{array}$} & None & $0[0.0]$ & $2[66.7]$ & $11[73.3]$ & $9[100]$ & \multirow[t]{5}{*}{$\mathrm{MC}$} & \multirow[t]{5}{*}{$<0.001^{1}$} \\
\hline & Deep infection-AVN & $2[66.7]$ & $0[0.0]$ & $0[0.0]$ & $0[0.0]$ & & \\
\hline & Neurapraxia of sciatic & $0[0.0]$ & 1[33.3] & $2[13.3]$ & $0[0.0]$ & & \\
\hline & Osteoarthritis & $1[33.3]$ & $0[0.0]$ & $0[0.0]$ & $0[0.0]$ & & \\
\hline & Superficial & $0[0.0]$ & $0[0.0]$ & $2[13.3]$ & $0[0.0]$ & & \\
\hline \multirow{3}{*}{$\begin{array}{l}\text { PO-operative } \\
\text { radiography }\end{array}$} & Unsatisfactory & $2[66.7]$ & $0[0.0]$ & $0[0.0]$ & $0[0.0]$ & \multirow[t]{3}{*}{$\mathrm{MC}$} & \multirow[t]{3}{*}{$<0.001^{*}$} \\
\hline & Satisfactory & $1[33.3]$ & $0[0.0]$ & $1[6.7]$ & $6[66.7]$ & & \\
\hline & Anatomical & $0[0.0]$ & $3[100]$ & 14[93.3] & $3[33.3]$ & & \\
\hline
\end{tabular}




\begin{tabular}{|c|c|c|c|c|c|c|c|}
\hline & & \multicolumn{4}{|c|}{ Late Radiological outcome } & \multirow[t]{2}{*}{ Test } & \multirow[t]{2}{*}{$p$} \\
\hline & & $\begin{array}{l}\text { Poor } \\
{[n=2]}\end{array}$ & $\begin{array}{l}\text { Fair } \\
{[n=1]}\end{array}$ & $\begin{array}{l}\text { Good } \\
{[n=15]}\end{array}$ & $\begin{array}{c}\text { Excellent } \\
{[n=11]}\end{array}$ & & \\
\hline \multicolumn{2}{|l|}{ Age/years } & $36.33 \pm 10.9$ & 48 & $33.53 \pm 9.456$ & $34.36 \pm 11.81$ & 0.619 & 0.609 \\
\hline \multirow[t]{2}{*}{ Sex } & Male & $3[100.0 \%]$ & $1[100.0 \%]$ & $14[93.3 \%]$ & $10[90.9 \%]$ & \multirow[t]{2}{*}{$\mathrm{MC}$} & \multirow[t]{2}{*}{0.942} \\
\hline & Female & $0[0.0 \%]$ & $0[0.0 \%]$ & $1[6.7 \%]$ & $1[9.1 \%]$ & & \\
\hline \multirow[t]{2}{*}{ Side } & Right & $0[0.0 \%]$ & $0[0.0 \%]$ & $8[50.0 \%]$ & $4[36.4 \%]$ & \multirow[t]{2}{*}{ MC } & \multirow[t]{2}{*}{0.219} \\
\hline & Left & $3[100.0 \%]$ & $0[0.0 \%]$ & $7[46.7 \%]$ & $7[63.6 \%]$ & & \\
\hline \multirow[t]{3}{*}{ Mechanism of injury } & FFH & $0[0.0 \%]$ & $0[0.0 \%]$ & $3[20.0 \%]$ & $0[0.0 \%]$ & \multirow[t]{3}{*}{ MC } & \multirow[t]{3}{*}{0.451} \\
\hline & $\mathrm{MCA}$ & $2[66.7 \%]$ & $0[0.0 \%]$ & $4[26.7 \%]$ & $3[27.3 \%]$ & & \\
\hline & RTA & $1[33.3 \%]$ & $1[100.0 \%]$ & $8[53.3 \%]$ & $8[72.7 \%]$ & & \\
\hline \multicolumn{2}{|l|}{ Time to support/day } & $6.33 \pm 1.155$ & $10.0 \pm 0.00$ & $6.67 \pm 2.48$ & $6.45 \pm 3.35$ & 0.510 & 0.679 \\
\hline \multicolumn{2}{|l|}{ Blood loss } & $933.33 \pm 57.735$ & $400 \pm 0.00$ & $1016 \pm 591.809$ & $977.27 \pm 477.684$ & KW & 0.766 \\
\hline \multicolumn{2}{|l|}{ Operative time } & $143.33 \pm 11.547$ & $180.0 \pm 0.00$ & $140.0 \pm 29.52$ & $133.64 \pm 32.33$ & 0.781 & 0.515 \\
\hline \multicolumn{2}{|c|}{ Blood transfusion units } & $2.0 \pm 0.0$ & $1.0 \pm 0.00$ & $2.07 \pm 1.223$ & $2 \pm 1.183$ & 0.265 & 0.850 \\
\hline \multirow{4}{*}{$\begin{array}{l}\text { Method of } \\
\text { fixation }\end{array}$} & Spring plate & $0[0.0 \%]$ & $0[0.0 \%]$ & $1[6.7 \%]$ & $2[18.2 \%]$ & $\mathrm{MC}$ & 0.694 \\
\hline & Double plating & $0[0.0 \%]$ & $0[0.0 \%]$ & $4[25.0 \%]$ & $3[27.3 \%]$ & $\mathrm{MC}$ & 0.793 \\
\hline & Anterior screw & $0[0.0 \%]$ & $0[0.0 \%]$ & $3[18.8 \%]$ & $0[0.0 \%]$ & MC & 0.405 \\
\hline & Plate screw & $3[100.0 \%]$ & $1[100.0 \%]$ & $11[73.3 \%]$ & $8[72.7 \%]$ & MC & 0.704 \\
\hline \multirow{5}{*}{$\begin{array}{c}\mathrm{PO} \\
\text { complications }\end{array}$} & Negative & $0[0.0 \%]$ & $0[0.0 \%]$ & $13[86.7 \%]$ & $9[81.8 \%]$ & \multirow[t]{5}{*}{ MC } & \multirow[t]{5}{*}{$<0.001^{*}$} \\
\hline & Deep infection \& AVN & $2[66.7]$ & $0[0.0 \%]$ & $0[0.0 \%]$ & $0[0.0 \%]$ & & \\
\hline & Neurapraxia of sciatic nerve & $0[0.0 \%]$ & $1[100.0 \%]$ & $2[13.3 \%]$ & $0[0.0 \%]$ & & \\
\hline & Osteoarthritis & $1[33.3 \%]$ & $0[0.0 \%]$ & $0[0.0 \%]$ & $0[0.0 \%]$ & & \\
\hline & Superficial & $0[0.0 \%]$ & $0[0.0 \%]$ & $0[0.0 \%]$ & $2[18.2 \%]$ & & \\
\hline \multirow{3}{*}{$\begin{array}{c}\text { Quality of } \\
\text { Reduction } \\
\text { [PO radiography] }\end{array}$} & Unsatisfactory & $2[66.7]$ & $0[0.0]$ & $0[0.0]$ & $0[0.0]$ & \multirow[t]{3}{*}{$\mathrm{MC}$} & \multirow[t]{3}{*}{$<0.001^{*}$} \\
\hline & Satisfactory & $0[0.0]$ & $0[0.0]$ & $1[33.3]$ & $7[63.6]$ & & \\
\hline & Anatomical & $0[0.0]$ & $1[100]$ & $15[100.0]$ & $4[36.4]$ & & \\
\hline
\end{tabular}

The next section presented a male patient, 48 years old, presented after motor car accident with fracture dislocation of posterior wall of the right acetabulum. At the time of admission, a closed reduction and skeletal traction were done then after 5 days, open reduction and internal fixation [ORIF] of fracture acetabulum by reconstruction plate and screws through posterior approach was completed [Figures .

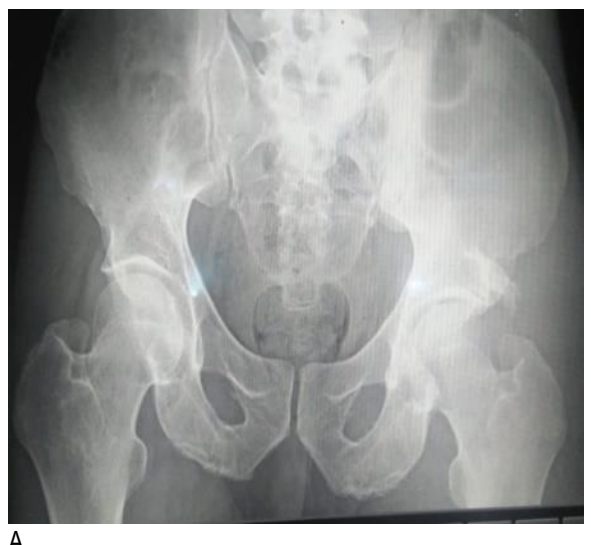

Figure [9]: Preoperative $\mathrm{x}$-ray of the patient showed fracture of posterior wall of the right acetabulum: A: Anteroposterior view, B: Obturator view and C: iliac view

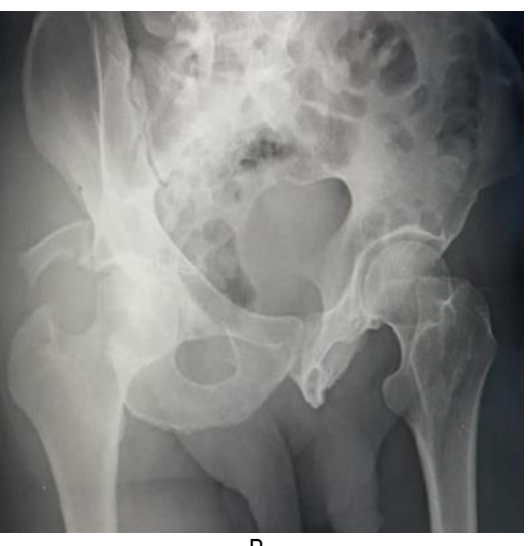

B

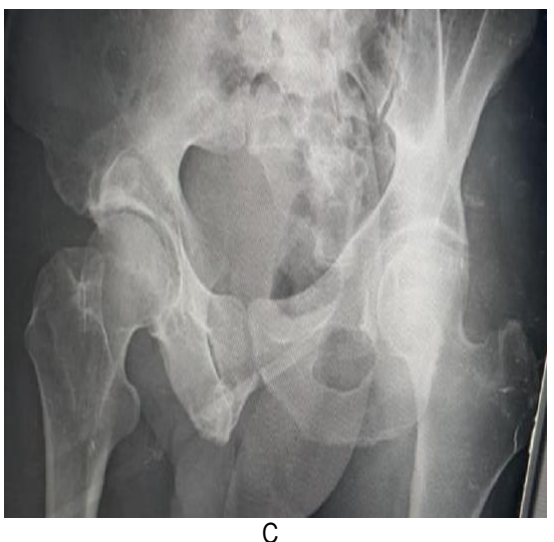

C 

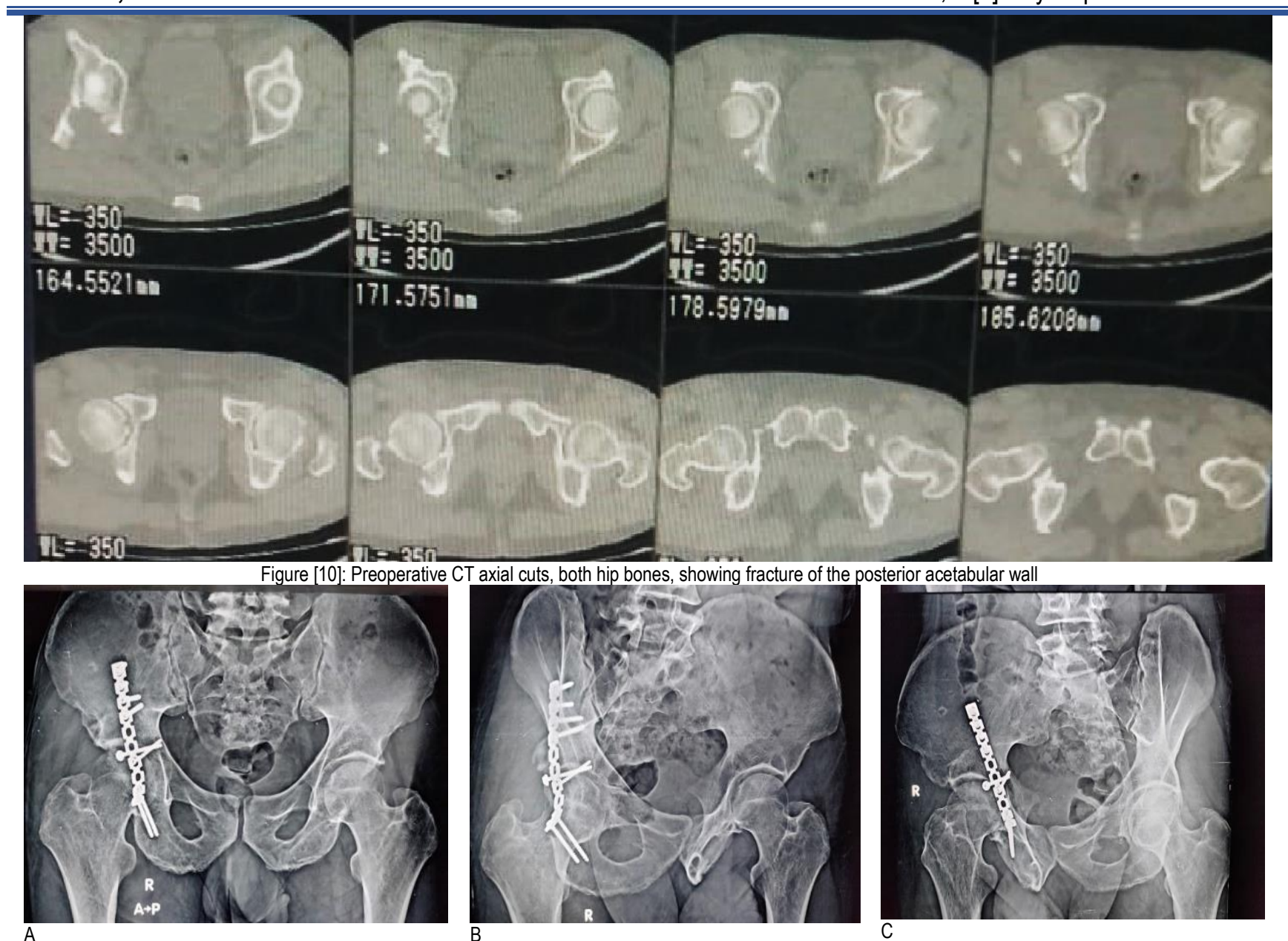

Figure [11]: Three months postoperative X-ray showing reconstruction $3.5 \mathrm{~mm}$, plate and screw fixation of postieor wall acetabular fracture. A: Anteroposterior view, B Obturator view and C: iliac view
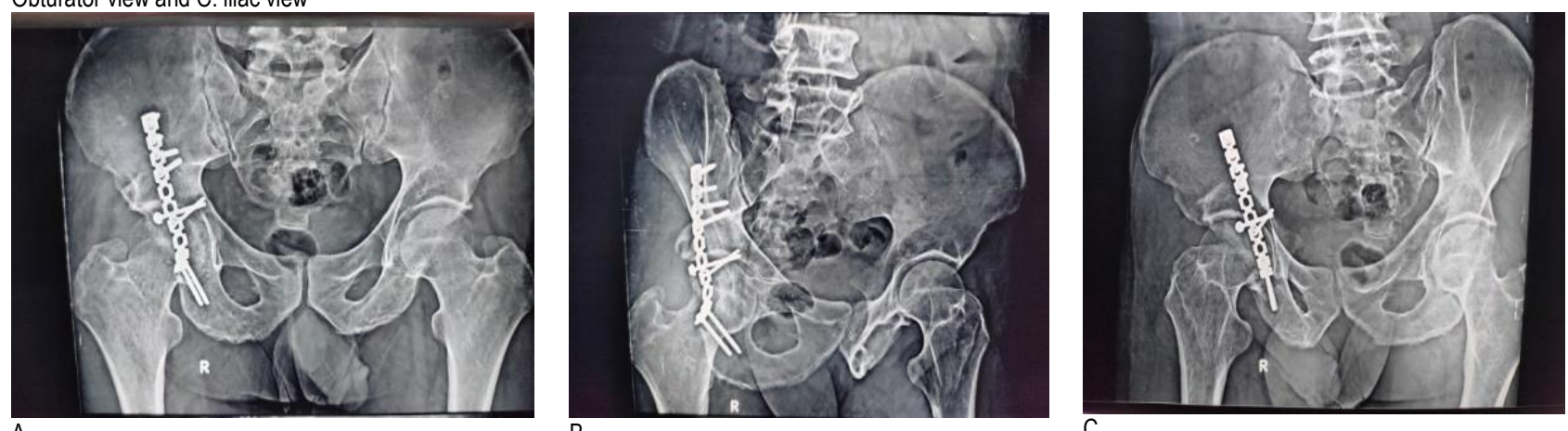

Figure [12]: Sixth months postoperative X-ray showing reconstruction $3.5 \mathrm{~mm}$, plate and screw fixation of posterior wall acetabular fracture. A: Anteroposterior view, B: Obturator view and C: iliac view

\section{DISCUSSION}

The aim of this study was to evaluate the short term results in management of acute posterior acetabular fractures by open reduction and internal fixation. Males represented the majority of the current study [28 males [93.3\%] and 2 females], and their age was around forties. This is compared to the study performed by Negrin and Seligson ${ }^{[14]}$, which included 111 males and 56 females with a mean of [ $41.8 \pm 15.1$ years]. In addition, the study of Islam et al. [15], where, there were 23 men and 2 women with a mean of $[38 \pm 11$ years].

In this study, the mechanism of injury was related to road traffic accidents [RTA] in $90 \%$ of patients, and $10 \%$ were attributed to falling from high [FFH]. This is compared to Mesbahi et al. [16]. There were $82.3 \%$ acetabular injuries due to road traffic accidents and $15.2 \%$ had falls from a significant height. 
Our patients were submitted to surgical intervention within two weeks of admission [ $46.7 \%$ within 5 days, $43.3 \%$ within $6-10$ days of admission $10.0 \%$ within $11-15$ days. This is compared to the study performed by Magu et al. [17] reported that, the average time between injury and surgical procedure was $4.2 \pm 1.7$ days [range $3-12$ days].

In the current work, 23 patients [76.7\%] had fixation by single $3.5 \mathrm{~mm}$ reconstruction plate and screws $[3.5 \mathrm{~mm}$ cortical and $4 \mathrm{~mm}$ cancellous] and 7 patients [23.3 \%] had fixation by double $3.5 \mathrm{~mm}$ reconstruction plate and screws. Three patients [ $10 \%$ ] had additional fixation by spring plates and 3 patients [10\%] had additional fixation by long anterior lag screw. This is in line with the study performed by Nortje et al. ${ }^{[18]}$ on 196 patients treated for posterior wall acetabular fractures from 1994 to 2006. In 125 [64\%] of these a reconstruction plate was used and in 71 [36\%] a one-third tubular plate was used. None of the reconstruction plates experienced any hardware failure. Two [3\%] of the one-third operated tubular plates had failed.

The complication rate was [26.7\%] of all cases in the form of 2 cases [6.7\%] had superficial infection which was treated by daily dressing and antibiotic till subsided, 3 cases [10\%] had neurapraxia of sciatic nerve which was treated by ankle foot orthosis and neurotonics and they improved within 3 months post-operative, 2 cases [6.7\%] had deep infection which was treated with surgical debridement till infection subsided and one case [3.3\%] developed avascular necrosis of the femoral head which was treated by total hip replacement. This is compared to a study performed by Moed et al. ${ }^{[19]}$ on 100 patients 94 patients were assessed at a mean of five years [range2-4 years] after the injury, 6 patients with a poor result were followed for less than two years, and reported one case [1\%] had deep infection, one patient [1\%] had superficial infection, 7 cases [7\%] developed deep vein thrombosis, and 7 cases [7\%] developed avascular necrosis of the femoral head. The variables recognized as risk factors for inadequate clinical outcomes included a delay of more than 12 hours before reduction of related hip dislocations, age 55 years or older at the time of injury, intra-articular comminuted, and osteonecrosis.

In the current work, spring hook plates, prepared from small fragment one-third tubular plates used in 3 cases [10\%] for stabilization of posterior wall fragments that are too small or too peripheral for lag screws. Richter et al. [20] evaluated posterior wall fractures with concentric comminution stabilized with reconstruction plates versus reconstruction plates and an underlying spring plate. The addition of the spring plate did not increase the stiffness of the fixation but did increase the ultimate yield strength.
Lee and Johnson [21] published a study of 52 patients who used custom spring plates as an auxiliary fixation device to undergo surgical treatment of acetabular fractures between 2000 and 2017 who met the inclusion criteria. The average age at first surgery was 41 years [range, 16-89 years]. Of 52 patients, 18 had additional joint edge impaction, requiring elevation and bone grafting. In addition to the spring plates, 25 patients also used separate lag screws. The average follow-up time was 14.2 months. They concluded that, one-third tubular plate used as a spring plate combined with the $3.5 \mathrm{~mm}$ overlay compression plate is an acceptable way to fix edges that are not suitable for lag screw fixation and / or rear wall debris crushed. The spring plate allows final fixation and stability of these broken fragments to allow patient movement without the significant risk of implant failure or hardware penetration into the joint.

In this study, three [10\%] cases had associated anterior column fracture were fixed by long lag 3.5 cortical screws up to $120 \mathrm{~mm}$ in length through the posterior approach under image guide. Razaq et al. [22] published a study of 25 adult patients from December 2013 to June 2015, including 18 men and 7 women, with acetabular fractures affecting the anterior and posterior columns. All patients were operated on by a surgical team within 8 days after injury. The Kockerlengenbeck approach was used to expose and reduce the posterior acetabular spine and the reconstruction plate and cortical screws were used for open reduction and internal fixation. After indirect reduction, additional lag screws were used to stabilize the anterior column, confirmed by the $\mathrm{C}$-arm and digital palpation through the ischial notch. They concluded that, in some cases, fractures involving two acetabular columns can be treated with a single posterior approach because it is associated with good clinical outcomes and involves fewer soft tissue complications. Hammad et al. [23] made a study on a group of 34 patients with T-shaped acetabular fractures were treated with a posterior plate and anterior screw. All patients were followed for at least two years. $62 \%$ of the patients achieved anatomical reduction, $82 \%$ of the patients achieved a satisfactory reduction of the anterior column and a recovery of the consistency of the hip joint, and $75 \%$ of the cases had excellent clinical results good. Residual anterior column displacement> $3.5 \mathrm{~mm}$ is associated with poor clinical outcomes.

The immediate post-operative radiological outcome according to Matta score depending on the highest displacement seen on the post-operative AP and Judet views was 20 [66.7\%] cases had anatomical reduction , 8 [26.7\%] cases had satisfactory reduction and 2 [6.7\%] had unsatisfactory reduction. This is compared to the study performed by lqbal et al. [24], where the immediate post- 
operative radiological outcome was anatomical reduction in 39 patients [78\%] 5 patients [10\%] had a satisfactory reduction and 6 patients [12\%] were unsatisfactory. Also the study performed by Pascarella et al. [25], where the quality of fracture reduction on postoperative radiographs was anatomical in 115 cases [95.0\%], satisfactory in 6 cases [5.0\%], and unsatisfactory in none.

In this study, the final clinical outcome was excellent in 9 [30\%] cases, good in $15[50 \%]$ cases, fair in 3 [10\%] cases and poor in $3[10 \%]$ cases. The radiological outcome was excellent in $11[36.7 \%]$ cases, good in $15[50 \%]$ cases, fair in $1[3.3 \%]$ cases and poor in $3[10 \%]$ cases. Several studies showed comparable results. A retrospective analysis of 22 patients with a mean age of 43.13 years was performed. All patients were treated with open reduction and internal fixation. All injured patients underwent surgery for 4 to 11 days [average 5.7 days]. According to the Judet and Letournel classification, 15 [68.18\%] patients had primary acetabular fractures and 7 [31.82\%] patients had fractures. A satisfactory postoperative reduction was achieved in 19 [86.36\%] patients, meaning that the displacement was less than $2 \mathrm{~mm}{ }^{[26]}$.

Xin et al. [27] conducted a retrospective analysis of 31 patients of average age 40.5 years. Where the final functional results were excellent in $48.4 \%$, good in $41.9 \%$, fair in $6.5 \%$ and poor in $3.3 \%$, Magu et al. ${ }^{[17]}$ conducted a retrospective analysis of 25 patients, one of whom had bilateral posterior wall fractures, with a mean age of $41.28 \pm$ 7.16 years [range 25-60]. 22 hips achieved anatomical reduction, 4 hips were imperfect and without difference. Final follow-up radiology results showed that 10 hips were excellent, 8 hips were good, 5 hips were fair, and 3 hips were bad. In the end, d'Aubigne 'and Postel's scores were excellent at 14 hips, 6 hips were good and neutral, and bad were three per person. They concluded that post-anatomy reduction can achieve the best functional and radiological results during long-term follow-up. Pascarella et al. [25] conducted a retrospective analysis of 121 patients. The final modified d'Aubignè score was excellent in 45 hips [40.2\%], good in 52 hips [46.4\%], in 7 hips [6.3\%] and poor in 8 hips [7.1\%]. At the final imaging exam, 85 hips were excellent $[75.2 \%], 16$ hips were good [14.2\%], 8 hips were fair [7.1\%], and 4 hips were poor [3.5\%].

In this study, Average follow up was 9 months [ranging from 6 and 12 months]. This is compared to the study of Pascarella et al. ${ }^{[25]}$, with average follow up assessed at a mean of 53 months [range, 24-163] after surgery, and the study of Nortje et al. ${ }^{118]}$, the patients were followed up for an average of 17 months clinically and with radiographs and the study of Lee \& Johnson [21], the mean follow-up was 13.9 months [range: 3-140 months].

\section{Conclusion:}

In this study most of the patients showing excellent and good outcome as a result to application of more strict selection criteria of patients and pattern. The main limitations of present study were the short duration of the follow up and small number of included patients.

Financial and Non-financial Relationships and Activities of Interest

None to be declared

\section{REFERENCES}

1. Verbruggen SW, Nowlan NC. Ontogeny of the Human Pelvis. Anat Rec [Hoboken]. 2017 Apr; 300 [4]: 643-652. DOI: 10.1002/ar.23541.

2. Pease $F$, Ward AJ, Stevenson AJ, Cunningham JL, Sabri O, Acharya $M$, Chesser T. Posterior wall acetabular fracture fixation: A mechanical analysis of fixation methods. J Orthop Surg [Hong Kong]. 2019; 27 [3]:2309499019859838. DOI: $10.1177 / 2309499019859838$.

3. McCullough AL, Haycock JC, Forward DP, Moran CG. Early management of the severely injured major trauma patient. $\mathrm{Br}$ J Anaesth. 2014;113[2]:234-41. DOI: 10.1093/bja/aeu235.

4. Bodanapally UK, Dattwyler M. Acetabular fractures: A Stepwise approach to identification and classification on 2D computed tomography. Applied Radiol. 2019; 48 [4]: 17-23. Available at: https://cdn.agilitycms.com/applied-radiology/PDFs/lssues/ AR_07-19_Bodanapally.pdf

5. Lal SR. Outcome of surgical treatment for displaced acetabular fractures: a prospective study. Rev Bras Ortop. 2017 Dec 29; 53 [4]: 482-488. DOI: 10.1016/j.rboe.2017.12.007.

6. Jang JH, Moon NH, Park KY. Arthroscopic Management of Intraarticular Screw Perforation after Surgical Treatment of an Acetabular Posterior Wall Fracture: A Case Report. Hip Pelvis. 2018 Mar;30[1]:60-64. DOI: 10.5371/hp.2018.30.1.60.

7. Su K, Liu S, Wu T, Yin Y, Zhang R, Li S, Zhang Y. Posterior column acetabular fracture fixation using a $\mathrm{W}$-shaped angular plate: A biomechanical analysis. PLoS One. 2017;12[11]: e0187886. DOI: 10.1371/journal.pone.0187886.

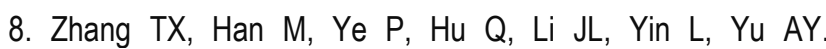
Interventional treatment experience in multiple injury with major abdominal or pelvic injuries: 160 cases analysis. Chin J Traumatol. 2018 Feb;21[1]:27-29. DOI: 10.1016/j.cjtee.2017. 11.003.

9. Dailey SK, Archdeacon MT. Open reduction and internal fixation of acetabulum fractures: does timing of surgery affect blood loss and OR time? J Orthop Trauma. 2014 Sep;28[9]:497-501. DOI: 10.1097/BOT.0000000000000153. 
10. Magu NK, Rohilla R, Singh A, Wadhwani J. Modified KocherLangenbeck approach in combined surgical exposures for acetabular fractures management. Indian J Orthop. 2016 MarApr; 50[2]:206-12. DOI: 10.4103/0019-5413.177570.

11. Bozzio AE, Johnson CR, Mauffrey C. Short-term results of percutaneous treatment of acetabular fractures: functional outcomes, radiographic assessment and complications. Int Orthop. 2016 Aug;40[8]:1703-1708. DOI: 10.1007/s00264015-2987-0.

12. Lieberthal J, Sambamurthy N, Scanzello CR. Inflammation in joint injury and post-traumatic osteoarthritis. Osteoarthritis Cartilage 2015;23[11]:1825-34. DOI: 10.1016/j.joca.2015.08. 015.

13. Ziran N, Soles GLS, Matta JM. Outcomes after surgical treatment of acetabular fractures: a review. Patient Saf Surg. 2019 Mar 16; 13:16. DOI: 10.1186/s13037-019-0196-2.

14. Negrin LL, Seligson D. Results of 167 consecutive cases of acetabular fractures using the Kocher-Langenbeck approach: a case series. J Orthop Surg Res. 2017 Apr 26; 12[1]: 66. DOI: 10.1186/s13018-017-0563-6.

15. Islam MN, Rahman MM, Islam MS, Kabir SJ, Alamgir MK, Kashem MT, et al. Outcome of Open Reduction and Internal Fixation of Posterior Wall Fracture of Acetabulum. Mymensingh Med J. 2020 Jul; 29 [3]: 502-508. PMID: 32844786.

16. Mesbahi SAR, Ghaemmaghami A, Ghaemmaghami S, Farhadi P. Outcome after Surgical Management of Acetabular Fractures: A 7-Year Experience. Bull Emerg Trauma. 2018 Jan;6[1]:37-44. DOI: 10.29252/beat-060106.

17. Magu NK, Gogna P, Singh A, Singla R, Rohilla R, Batra A, Mukhopadhyay R. Long term results after surgical management of posterior wall acetabular fractures. J Orthop Traumatol. 2014 Sep;15[3]:173-9. DOI: 10.1007/s10195-0140297-8.

18. Nortje MB, Siboto GM, Walters J. Posterior acetabular wall fracture fixation with a one-third tubular plate. SA Orthopaedic J. 2009; 24-29. Available at: http://www.scielo.org.za/scielo. php? script=sci_arttext\&pid=\$1681-150X2009000200005
19. Moed BR, WillsonCarr SE, Watson JT. Results of operative treatment of fractures of the posterior wall of the acetabulum. J Bone Joint Surg Am. 2002 May;84[5]:752-8. DOI: 10.2106/ 00004623-200205000-00008.

20. Richter H, Hutson JJ, Zych G. The use of spring plates in the internal fixation of acetabular fractures. J Orthop Trauma. 2004 Mar;18[3]:179-81. DOI: 10.1097/00005131-20040300000010.

21. Lee Lee C, Johnson EE. Use of Spring Plates in Fixation of Comminuted Posterior Wall Acetabular Fractures. J Orthop Trauma. 2018;32 Suppl 1: S55-S59. DOI: 10.1097/BOT. 0000000000001089.

22. Razaq MN, Khan MA, Ali A. Outcome of Two Column Acetabular Fractures Treated Operatively Through Single Posterior Approach. J Ayub Med Coll Abbottabad. 2016 OctDec; 28[4]:718-720. PMID: 28586601.

23. Hammad AS, El-Khadrawe TA, Waly AH, Abu-Sheasha GA. The efficacy of posterior plating and anterior column screw fixation in the management of T-shaped acetabular fractures CART analysis of prospective cohort study. Injury. 2017; 48 [3]: 680-686. DOI: 10.1016/j.injury. 2017.01.024.

24. Iqbal F, Taufiq I, Najjad MK, Khan N, Zia OB. Fucntional and Radiological Outcome of Surgical Management of Acetabular Fractures in Tertiary Care Hospital. Hip Pelvis. 2016 Dec; 28[4]:217-224. DOI: 10.5371/hp.2016.28.4.217.

25. Pascarella R, Cerbasi S, Politano R, Balato G, Fantasia R, Orabona $G$, Mariconda M. Surgical results and factors influencing outcome in patients with posterior wall acetabular fracture. Injury. 2017 Aug;48[8]:1819-1824. DOI: 10.1016/ j. injury.2017.05.039.

26. Milenković S, Saveski J, Radenković M, Vidić G, Trajkovska N. Surgical treatment of displaced acetabular fractures. Srp Arh Celok Lek. 2011;139[7-8]:496-500. PMID: 21980661.

27. Xin QI, Jian-guo LIU, Yu-bao GONG, Chen YANG, Shu-qiang $\mathrm{LI}$, FENG Wei. Treatment of posterior wall fractures of acetabulum. Chinese J Traumatol 2009; 12 [2]: 113-117v 

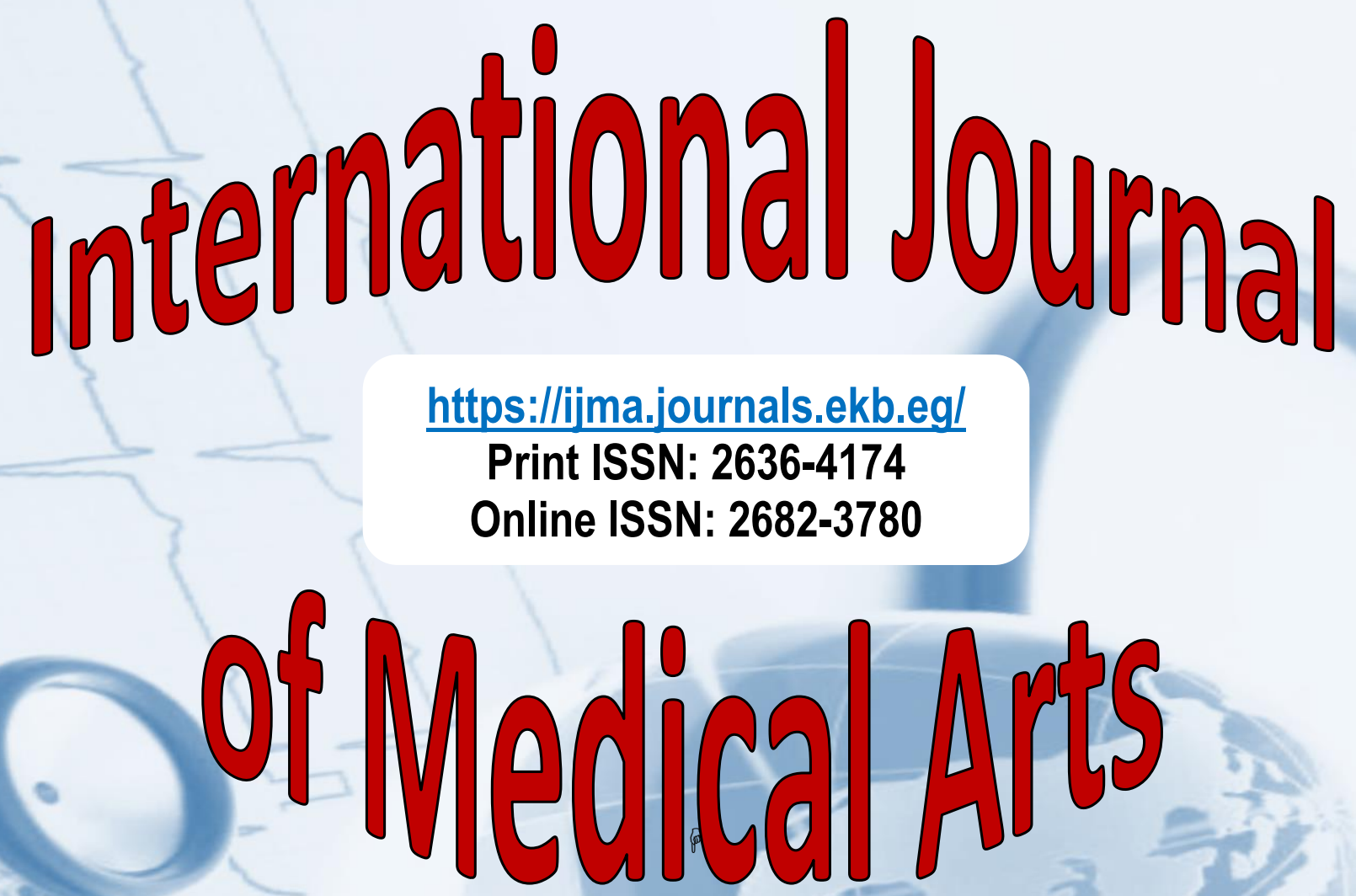